\title{
NUCLEOLAR ACTIVITY AND COMPETITION (AMPHIPLASTY) IN THE GENUS AEGILOPS
}

\author{
M. C. CERMEÑo, J. ORELLANA, J. L. SANTOS AND J. R. LACADENA \\ Departamento de Genética, Facultad de Biologia, Universidad Complutense, 20840 Madrid, \\ Spain
}

Received 20.iii.84

\section{SUMMARY}

\begin{abstract}
Nucleolar activity and competition (amphiplasty) has been analysed in diploid, tetraploid and hexaploid species of Aegilops using a highly reproducible silverstaining procedure. A comparative analysis of somatic metaphase chromosomes by phase contrast, C-banding and Ag-staining was made to analyse the activity of the nucleolar organiser regions (NORs). With the exception of Ae. crassa $4 x$, amphiplasty occurs in all the tetraploid and hexaploid species analysed. The $U$ genome from $A$ e. umbellulata suppresses completely the NOR activity of the genomes $M^{\circ}$ (Ae. ovata), $S^{v}$ (Ae. variabilis), $D$ (Ae. juvenalis) and $C$ (Ae. triuncialis) and that of one pair of the nucleolar organiser chromosomes of the genomes $M^{c}$ (Ae. columnaris), $M^{b}$ (Ae. biuncialis), $M^{s}$ (Ae. juvenalis) and $M^{t}$ (Ae. triaristata $6 x$ ). The nucleolar activity of the $D$ genome is completely suppressed by the genomes $U$ (Ae, umbellulata), $C$ (Ae. cylindrica) and $M^{v}$ (Ae. ventricosa).
\end{abstract}

\section{INTRODUCTION}

Nucleolus organiser regions (NORs), which are associated with secondary constrictions of satellited chromosomes, have been shown to be the sites of ribosomal RNA genes. Differential amphiplasty, that is changes affecting individual chromosomes of the complement following interspecific hybridisation (Rieger et al., 1976), was first described by Navashin (1928, 1934) in Crepis where the secondary constriction of the SAT-chromosomes of one of the parental species was absent in hybrids. The satellite was retracted onto the chromosome and the corresponding NOR is not distinguishable.

Highly reproducible silver-staining methods have been recently developed for the differential staining of the NORs (Ag-NORs) of plant chromosomes (Hizume et al., 1980; Sato et al., 1980; Lacadena et al., 1984a). The silver procedure can be used to visualise gene activity at the rDNA sites with conventional light microscopy since only those NORs which were functionally active during the preceding interphase are stained by silver (Miller et al., 1976a, 1976b; see review by Howell, 1982). Recently, Medina et al. (1983) concluded that Ag-NOR staining is associated with decondensed NOR chromatin, rather than active NOR chromatin. In other words, all the active NOR chromatin is detected by silver-staining but not all the Ag-NOR-stainable structures contain active NOR chromatin.

It was recently pointed out (Lacadena et al., 1984a; Cermeño et al., 1984) that the Ag-staining method could be very useful for the analysis of nucleolar competition (amphiplasty) in allopolyploid species. This is the case in the genus Aegilops. The occurrence of amphiplasty in polyploid species of Aegilops has been reported both by conventional light microscopy (Chennaveeraiah, 1960) and by in situ hybridisation of labelled ribosomal 
RNA to metaphase chromosomes (Teoh et al, 1983a). These authors concluded that in the polyploid Aegilops species the number of sites of rRNA gene clusters was consistently higher than the number of satellited thromosomes as observed by conventional light microscopy and suggested that this discrepancy is probably due to the inactivation of some nucleolar organiser regions when different genomes combine together.

The aim of this paper is to analyse the nucleolar activity and the occurrence of nucleolar competition (amphiplasty) in the genus Aegilops by using a highly reproducible silver-staining procedure developed by Lacadena et al. (1984a).

\section{MATERIAL AND METHODS}

\section{(i) Material}

The following species were used:

(a) Diploid species $(2 n=2 x=14)$

Aegilops umbellulata (genome constitution, UU), Ae. comosa (MM), Ae. uniaristata $\left(M^{u} M^{u}\right)$, Ae. caudata $(C C)$, Ae. squarrosa (DD), Ae. speltoides (SS), Ae. longissima $\left(S^{1} S^{1}\right)$, Ae. sharonensis $\left(S^{I} S^{\prime}\right)$ and Ae. bicornis $\left(S^{b} S^{b}\right)$.

(b) Tetraploid species $(2 n=4 x=28)$

Ae. ovata $\left(U U M^{o} M^{o}\right)$, Ae. columnaris $\left(U U M^{c} M^{c}\right)$, Ae. biuncialis $\left(U U M^{b} M^{b}\right), A e$. variabilis (UUS $\left.S^{v}\right), A e$ triuncialis (UUCC), Ae. cylindrica (CCDD), Ae. ventricosa $\left(D D M^{v} M^{v}\right)$ and Ae. crassa $4 x$ $\left(D D M^{c r} M^{c r}\right)$.

(c) Hexaploid species $(2 n=6 x=42)$

Ae. triaristata (UUM $\left.M^{t} M^{t} M^{t 2} M^{t 2}\right)$, Ae. crassa $6 x\left(D D D^{2} D^{2} M^{c r} M^{c r}\right)$ and Ae. juvenalis $\left(D D U U M^{j} M^{j}\right)$.

This material was obtained from the collections of the Plant Breeding Institute, Cambridge, UK (kindly supplied by H. Guedes-Pinto, IUTAD, Vila Real, Portugal) and from the Estación Experimental de Aula Dei, Zaragoza, Spain.

\section{(ii) Methods}

Seeds were germinated on wet filter paper in Petri dishes at $20^{\circ} \mathrm{C}$. When primary roots were $1 \mathrm{~cm}$ long they were excised and immersed in tap water at $0^{\circ} \mathrm{C}$ for $36-48 \mathrm{~h}$ to contract the chromosomes. The root tips were subsequently fixed in 1:3 acetic acid:ethyl alcohol.

The C-banding procedure was carried out according to Giraldez et al. (1979).

The silver-staining procedure for nucleolar organiser regions, based on Hizume et al. (1980), was described by Lacadena et al. (1984a).

A comparative analysis of metaphase somatic cells by phase contrast, $\mathrm{C}$-banding and Ag-staining was made. The nucleolar organiser chromosomes (SAT-chromosomes) were identified both with phase contrast and C-banding from comparisons of the same metaphase cells. On the other hand, silver-stained nucleolar organiser regions (Ag-NORs) were also clearly identified, being located in close correspondence with the secondary constrictions as observed previously by phase contrast of the same cells. 
Interphase nucleoli were observed by silver-staining. Contingency tests indicated that the distributions of the number of nucleoli found in the different plants of each species were homogeneous and, consequently, individual data have been combined.

\section{Results AND discussion}

The number of silver-stained nucleolar organiser regions (Ag-NORs) and nucleoli observed, respectively, at somatic metaphase and interphase cells in diploid, tetraploid and hexaploid species of Aegilops are shown in table 1. The maximum number of nucleoli observed in each species agrees with that of the corresponding Ag-NORs. Only in a few cases (Ae. comosa, Ae. speltoides, Ae. columnaris, Ae. biuncialis, Ae. juvenalis) the Ag-staining

\section{TABLE 1}

Silver-stained nucleolar organiser regions (Ag-NORs) and numbers of observed nucleoli at somatic metaphase and interphase cells, respectively, in diploid, tetraploid and hexaploid species of Aegilops

\begin{tabular}{|c|c|c|c|c|c|c|c|c|c|c|c|}
\hline \multirow[b]{2}{*}{ Species } & \multirow{2}{*}{$\begin{array}{l}\text { No. of } \\
\text { plants }\end{array}$} & \multirow{2}{*}{$\begin{array}{c}\text { No. of } \\
\text { metaphase } \\
\text { cells } \\
\text { scored }\end{array}$} & \multirow[b]{2}{*}{ Ag-NORs } & \multicolumn{8}{|c|}{ No. of nucleoli at interphase } \\
\hline & & & & 1 & 2 & 3 & 4 & 5 & 6 & 7 & 8 \\
\hline \multicolumn{12}{|l|}{ Diploid } \\
\hline Ae. umbellulata & 5 & 36 & 4 & 153 & 292 & 64 & 12 & - & - & - & - \\
\hline Ae. comosa & 2 & $\left\{\begin{array}{l}4 \\
2\end{array}\right.$ & $\left.\begin{array}{l}4 \\
2\end{array}\right\}$ & 38 & 121 & 42 & 7 & - & - & - & - \\
\hline 16. uniaristata & 5 & 30 & 2 & 262 & 269 & - & - & - & - & - & 一 \\
\hline Ae. caudata & 4 & 18 & 4 & 83 & 227 & 79 & 18 & - & - & - & 一 \\
\hline Ae. squarrosa & 4 & $\begin{array}{r}12 \\
2\end{array}$ & $\begin{array}{l}2 \\
4)\end{array}$ & 240 & 182 & - & - & - & - & - & - \\
\hline Ae. speltoides & 5 & $\left\{\begin{array}{r}1 \\
20\end{array}\right.$ & $\left.\begin{array}{l}3 \\
2\end{array}\right\}$ & 486 & 491 & 116 & 15 & - & - & - & 一 \\
\hline Ae. longissima & 5 & 14 & 4 & 148 & 273 & 82 & 16 & - & - & - & - \\
\hline Ae. sharonensis & 4 & 23 & 4 & 207 & 179 & 46 & 4 & - & - & - & - \\
\hline Ae. bicornis & 4 & 18 & 4 & 148 & 152 & 76 & 14 & - & - & - & 一 \\
\hline \multicolumn{12}{|l|}{ Tetraploid } \\
\hline Ae. ovata & 3 & 12 & 4 & 22 & 175 & 99 & 15 & - & - & - & - \\
\hline Ae. columnaris & 5 & $\begin{array}{r}\left\{\begin{array}{r}3 \\
13\end{array}\right. \\
(2)\end{array}$ & $\left.\begin{array}{l}5 \\
4 \\
6\end{array}\right\}$ & 62 & 227 & 201 & 77 & 21 & 8 & - & - \\
\hline Ae. biuncialis & 5 & $\left\{\begin{array}{r}11 \\
7\end{array}\right.$ & $\left.\begin{array}{l}5 \\
4\end{array}\right\}$ & 114 & 183 & 127 & 73 & 14 & 1 & - & 一 \\
\hline Ae. variabilis & 5 & 21 & 4 & 103 & 277 & 114 & 28 & - & - & - & - \\
\hline Ae. triuncialis & 4 & 23 & 4 & 115 & 211 & 88 & 16 & - & - & - & - \\
\hline Ae. cylindrica & 4 & 22 & 4 & 157 & 191 & 74 & 9 & - & - & - & 一 \\
\hline Ae. ventricosa* & 6 & 41 & 2 & 345 & 255 & - & - & - & - & - & - \\
\hline Ae. crassa $4 x$ & 5 & 26 & 4 & 108 & 221 & 167 & 25 & - & - & - & - \\
\hline \multicolumn{12}{|l|}{ Hexaploid } \\
\hline Ae. triaristata & 5 & 14 & 6 & 47 & 191 & 164 & 85 & 20 & 5 & - & - \\
\hline Ae. crassa $6 x$ & 4 & 12 & 6 & 5 & 62 & 146 & 148 & 51 & 19 & - & 一 \\
\hline Ae. juvenalis & 5 & 1 & $\left.\begin{array}{l}6 \\
4\end{array}\right\}$ & 57 & 173 & 193 & 90 & 13 & 6 & - & - \\
\hline
\end{tabular}

* Data taken from Orellana et al. (1984). 


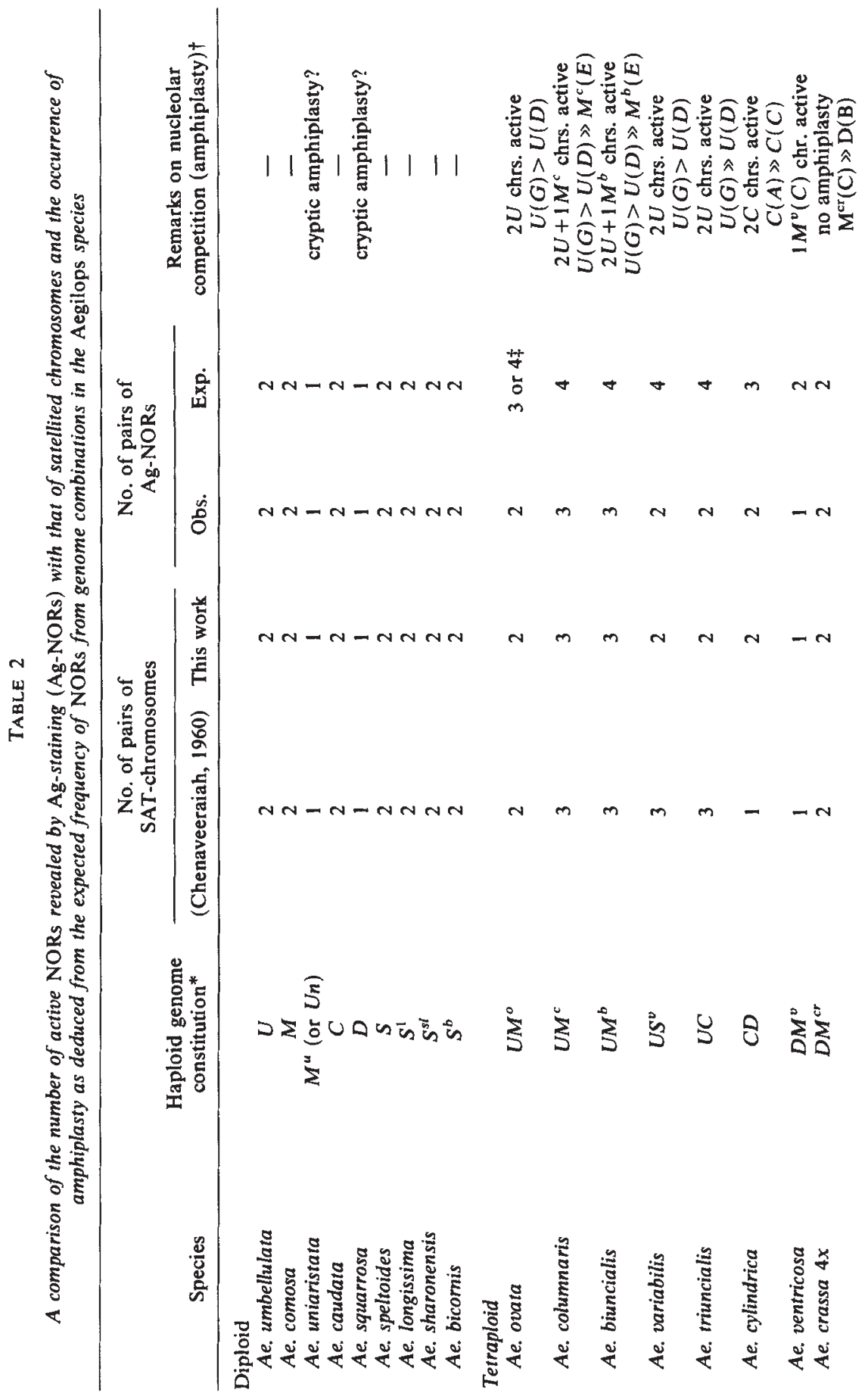




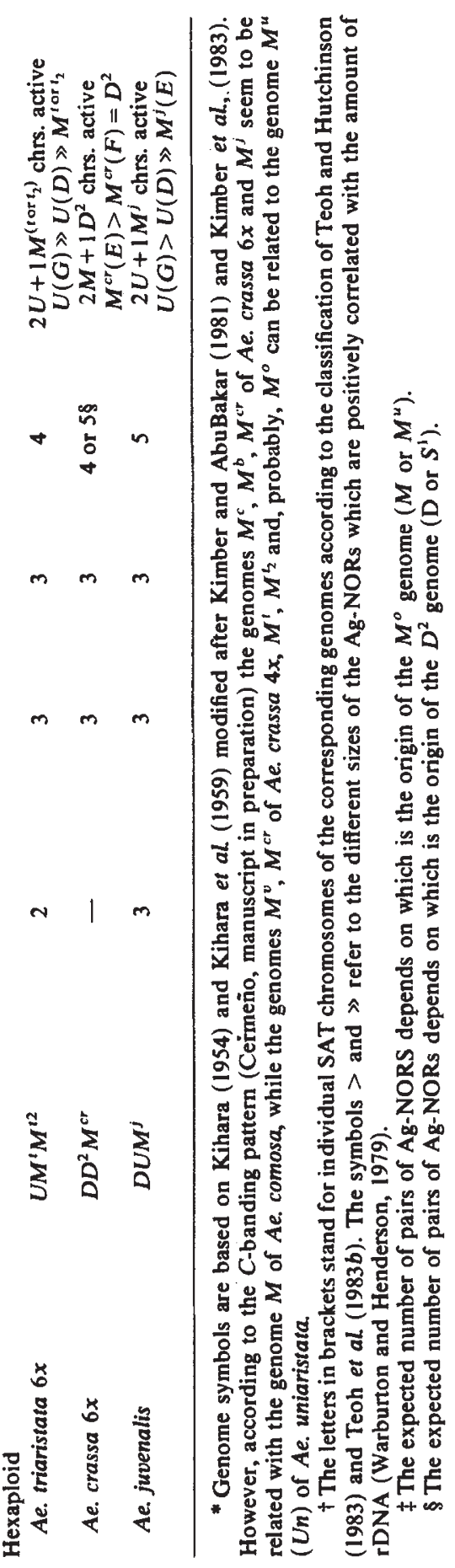


seems to have insufficient resolving power to reveal all the active NORs; however, the maximum number of nucleoli fit in with the expectations.

Taking into account the genome constitutions, the occurrence of nucleolar competition (amphiplasty) becomes apparent both in tetraploid and hexaploid species (table 2). Based on the C-banding patterns (Cermeño, manuscript in preparation) it has been possible to identify which chromosomes maintain nucleolar activity (plates 1 to 3 ).

As previously suggested (Lacadena et al., 1984a; Cermeño et al., 1984), the Ag-staining method has proven to be very useful in analysing natural amphiplasty in an allopolyploid taxomic group as Aegilops.

The numbers of satellited chromosomes observed by phase contrast of metaphase cells (table 2) agree with those described by Chennaveeraiah (1960) with a few discrepancies, namely, Ae. variabilis ( 2 instead of 3 pairs) Ae. cylindrica ( 2 instead of 1 pair), Ae. triaristata ( 3 instead of 2 pairs), Ae. triuncialis ( 2 instead of 3 pairs). However, it is worth mentioning that in our observations the number of satellited chromosomes, as seen by phase contrast, are in quite good agreement with the Ag-NORs and the maximum number of nucleoli observed.

All the diploid Aegilops species analysed show two pairs of nucleolus organiser chromosomes excepting Ae. uniaristata (genome $M^{u}$ or $U n$, see below) and Ae. squarrosa (genome $D$ ). Certainly, the occurrence of a cryptic amphiplasty cannot be inferred since it might be possible that both genomes have actually only one pair of nucleolus organiser chromosomes. Anyway, this situation represents an additional reason to consider the genome $M^{u}$ as different from the genome $M$ of Ae. comosa. In fact, Kimber et al. (1983), on the basis of the $M-M^{u}$ meiotic pairing in certain hybrids, suggested that the $M^{u}$ genome of Ae. uniaristata (Triticum uniaristatum) be changed to $U n$.

With the exception of Ae. crassa $4 x$, amphiplasty occurs in all the tetraploid and hexaploid Aegilops species analysed. Nevertheless, in $A e$. crassa $4 x$ the nucleolar activity of the chromosome " $C$ " of the $M$ genome is much higher than that of chromosome " $B$ " of the $D$ genome. So, it might be considered as a partial amphiplasty. The chromosomes " $C$ " and " $B$ " are named according to their resemblance to the $C$-banding patterns of the donor diploid species as described by Teoh and Hutchinson (1983).

The identification of the satellited chromosomes and their assignment to a determined genome was made according to their morphological characteristics and C-banding patterns after Cermeño's data (manuscript in preparation).

In all the species in which the genome $U$ from Ae. umbellulata is present (Ae. ovata, Ae. columnaris, Ae. biunncialis, Ae. variabilis, Ae. triuncialis, Ae. triaristata and Ae. juvenalis) its two pairs of nucleolar organiser chromosomes are active. In all cases the activity (measured by the NOR size, Warburton and Henderson, 1979) is higher in the " $G$ " chromosome than in the " $D$ " chromosome (according to the terminology used by Teoh and Hutchinson, 1983).

It is worthy of mention that in Ae. triuncialis and in Ae. triaristata $6 x$ the size of the Ag-NORs of chromosome " $G$ " is much larger than that of chromosome " $D$ " (plate 4 ). The strong activity of the " $G$ " chromosome resembles that of chromosomes $6 H^{v}$ of Hordeum vulgare (Santos et al., 1984) and $6 B$ of durum and common wheats (Cermeño et al., 1984). 

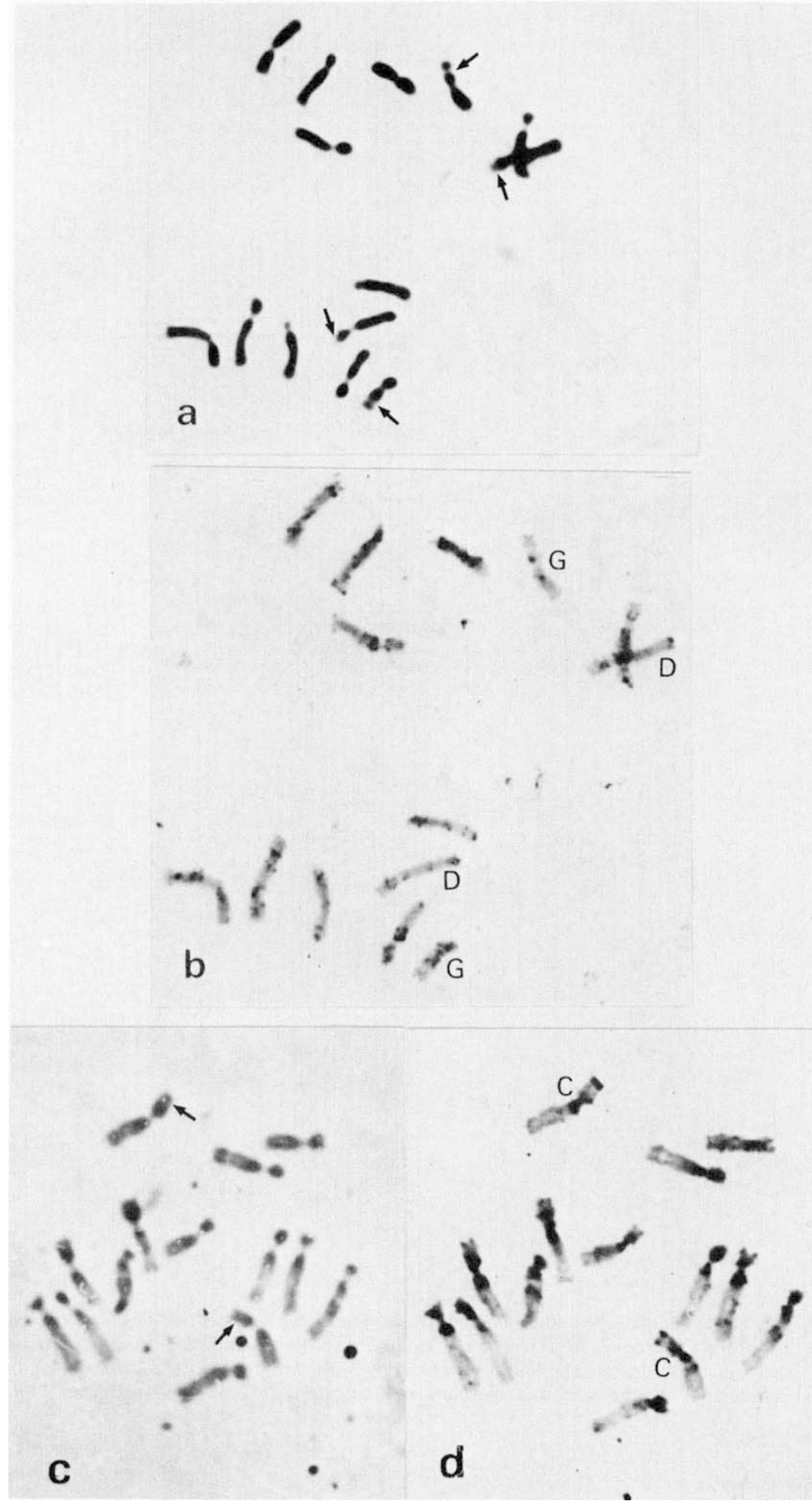

Plate 1. Phase contrast and $C$-banded somatic metaphase cells of Aegilops umbellulata (a and b) and Aegilops uniaristata ( $c$ and d). Note the very small sizes of satellites of chromosomes D in Ae. umbellulata. The letters representing SAT chromosomes correspond with Teoh and Hutchinson's (1983) classification. 

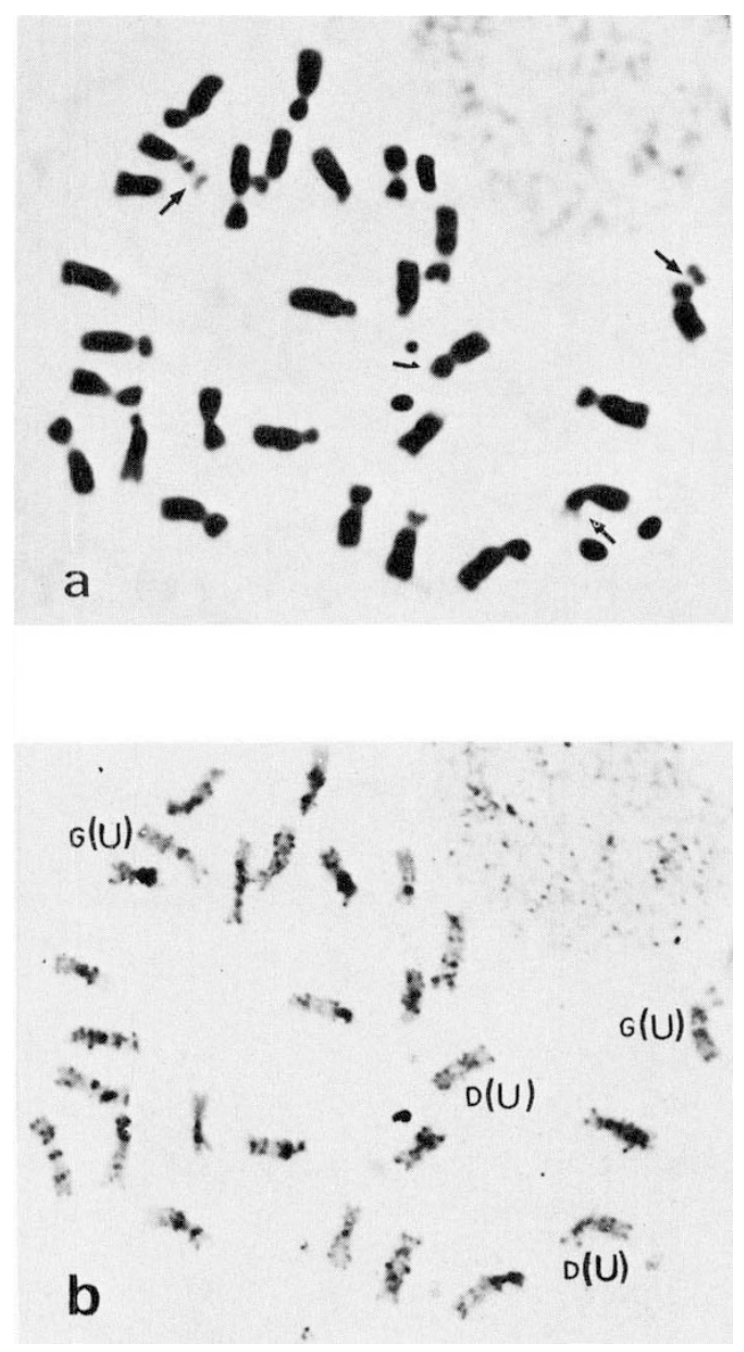

Plate 2. Phase contrast (a) and C-banded (b) somatic metaphase cells of Aegilops triuncialis. One of the $\mathrm{D}$ chromosomes from the $U$ genome has a very small satellite which is usually hardly distinguishable. The letters representing SAT chromosomes stand for the genome (in brackets) and the individual chromosomes according to Teoh and Hutchinson (1983). 

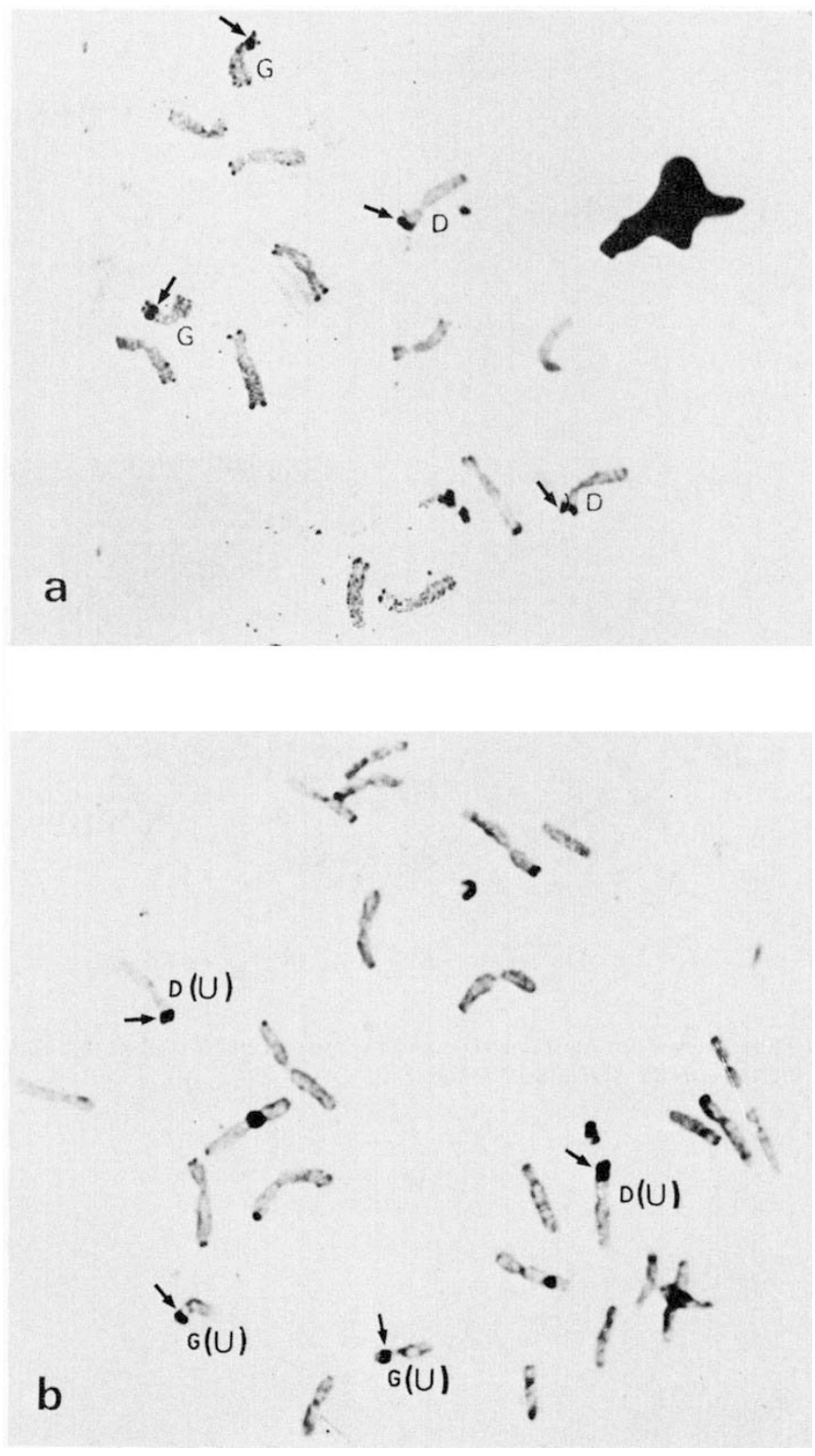

Plate 3. Ag-stained somatic metaphase cells of Aegilops umbellulata (a) and Aegilops triuncialis (b) showing $\mathrm{Ag}$-NORs indicated by arrows. 


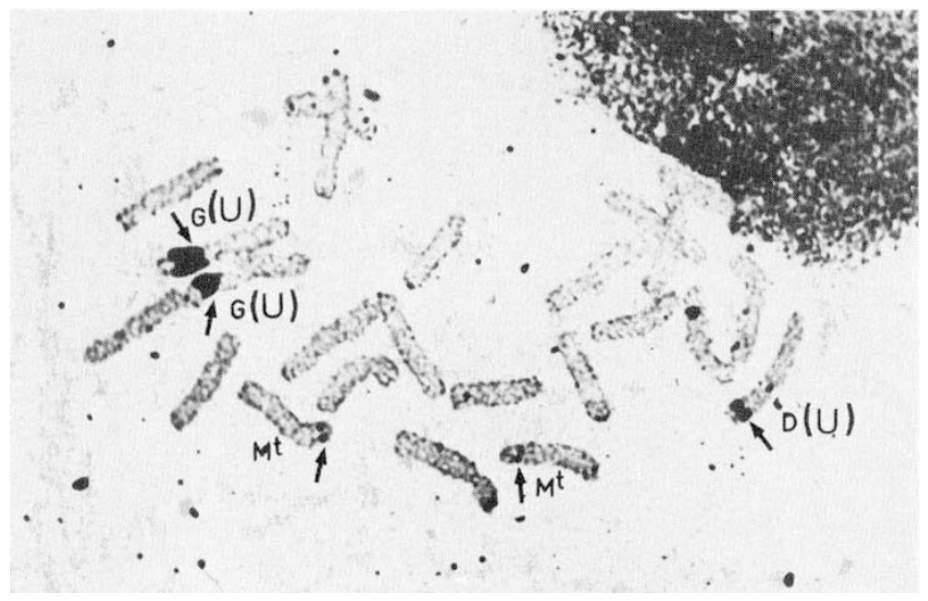

Plate 4. Partial view of an Ag-stained somatic metaphase cell of Aegilops triaristata showing the different sizes of Ag-NORs (see the text). 


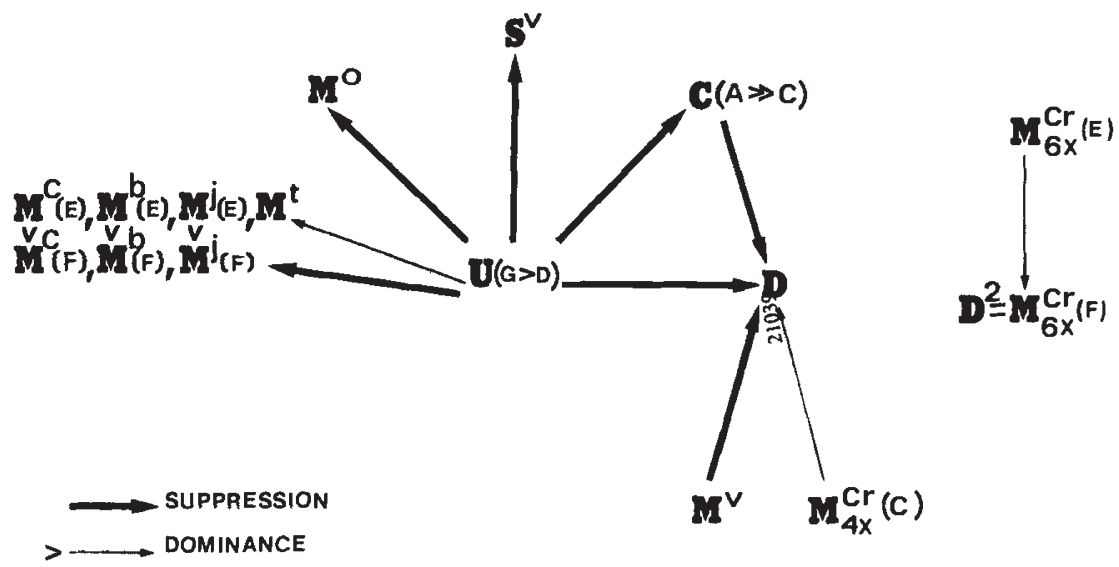

FiG. 1. Diagram showing nucleolar suppression and dominance relationships between the different genomes of Aegilops species. Letters in brackets represent SAT chromosomes of the corresponding genomes.

It is also to be noted that the presence of the $U$ genome seems to suppress completely the nucleolar activity of the chromosomes of the genomes $M^{o}$ (Ae. ovata), $S^{v}$ (Ae. variabilis) and $C$ (Ae. triuncialis). In addition, in the other polyploid species in which some nucleolar organiser chromosomes show activity it is very low (small sizes of the Ag-NORs); such is the case of Ae. columnaris, Ae. biuncialis, Ae. triaristata $6 x$ and Ae. juvenalis. This strong nucleolar activity of the $U$ genome was suggested by Martini et al. (1982) reporting the partial suppression of the nucleolar organising activity of wheat chromosomes by the presence of the $U$ chromosomes in Triticum aestivum-Ae. umbellulata chromosome addition lines.

In $A e$. cylindrica $(C C D D)$ the nucleolar activity of the $D$ genome chromosomes is suppressed by the presence of the $C$ genome as in $A e$. ventricosa $\left(D D M^{v} M^{v}\right)$ where the $M^{v}$ genome also suppresses the nucleolar activity of the $D$ genome chromosomes (Orellana et al., 1984). The $D$ genome chromosomes are also inhibited in the hexaploid species $A e$. juvenalis $\left(D D U U M^{j} M^{j}\right)$ and Ae. crassa $6 x\left(D D D^{2} D^{2} M^{c r} M^{c r}\right)$. In the latter species, the $D^{2}$ genome might be related to the $S^{1}$ better than to the $D$ genome according to its $C$-banding pattern (Cermeño, manuscript in preparation) and morphological characteristics (Kihara, 1963). As indicated above, the nucleolar organiser chromosome of the $D$ genome only seems to be active (although at a very low level) in the tetraploid Ae. crassa $\left(D D M^{c r} M^{c r}\right)$. This weak activity of the nucleolar organiser chromosome of the $D$ genome agrees with its behaviour in hexaploid wheat, Triticum aestivum (Cermeño et al., 1984).

Summing up, all the above data can be diagramatically represented as indicated in the fig. 1. A graded series of nucleolar activity including chromosomes of Triticum aestivum, Hordeum vulgare, Secale cereale, Agropyron elongatum and Aegilops ventricosa has been suggested by Lacadena et al. (1984b).

The evolutionary relationships between the genomes of the diploid species of the genus Aegilops as well as their modified genomes present in the tetraploid and hexaploid species have been extensively analysed (Kihara, 
1954, 1963; Kihara et al., 1959; Zohary and Feldman, 1962; Kimber and AbuBakar, 1981; Kimber et al., 1983; Kimber and Zhao, 1983). However, the comparative analysis of the $C$-banding pattern has not been used to study the genomic relationships of polyploid Aegilops species. Until now such an analysis has only been made in diploid species (Teoh and Hutchinson, 1983; Teoh et al., 1983b). From our observations (Cermeño, manuscript in preparation) it can be suggested that according to their $C$-banding patterns, the genomes $M^{c}, M^{b}, M^{c r}$ (of Ae. crassa $6 x$ ) and $M^{j}$ seem to be related with the genome $M$ of $A e$. comosa while the genomes $M^{v}, M^{c r}$ (of Ae. crassa $4 x$ ), $M^{t}, M^{t_{2}}$ and, probably, $M^{o}$ can be considered related to the genome $M^{\mu}(U n)$ of Ae. uniaristata.

Acknowledgment. This work was supported by a grant from the Comisión Asesora de Investigación Científica y Técnica of Spain.

\section{REFERENCES}

CERMEÑo, M. C., ORELLANA, J., SANTOS, J. L. AND LACADENA, J. R. 1984. Nucleolar organizer activity in wheat, rye and derivatives analyzed by a silver-staining procedure. Chromosoma, $89,370-376$.

CHENNAVEERA1AH, M. S. 1960. Karyomorphological and cytotaxonomic studies in Aegilops. Acta Horti. Gotoburgensis, 23, 85-178.

GIRALDEZ, R., CERMEÑO, M. C. AND ORELlANA, J. 1979. Comparison of C-banding pattern in the chromosomes of inbred lines and open pollinated varieties of rye, Secale cereale $\mathrm{L}$. Z. Pflanzenzüchtg., 83, 40-48.

HIZUME, M., SATO, S. AND TANAKA, A. 1980. A highly reproducible method of nucleolus organizer regions staining in plants. Stain Technol., 55, 87-90.

HOWELL, W. M. 1982. Selective staining of nucleolus organizer regions (NORs). The Cell Nucleus, 11, 89-142.

KIHARA, H. 1954. Considerations on the evolution and distribution of Aegilops species based on the analyser-method. Cytologia, 19, 336-357.

KIHARA, H. 1963. Interspecific relationships in Triticum and Aegilops. Seiken Ziho, 15, 1-12.

KIHARA, H., YAMASHITA, H. AND TANAKA, M. 1959. Genomes of $6 x$ species of Aegilops. Wheat Inform. Service, 8, 3-5.

KIMBER, G. AND ABUBAKAR, M. 1981. The genomic relationships of Triticum dichasians and T. umbellulatum. Z. Pflanzenzüchtg., 87, 265-273.

KIMBER, G., PIGNONE, D. AND SALLEE, P. J. 1983. The relationships of the $M$ and $M^{\text {u }}$ genomes of Triticum. Can. J. Genet. Cytol., 25, 509-512.

Kimber, G. AND ZHAO, Y. H. 1983. The $D$ genome of the Triticeae. Can. J. Genet. Cytol., 25, 581-589.

LACADENA, J. R., CERMEÑo, M. C., ORELlanA, J. AND SANTOS, J. L. 1984a. Evidence for wheat-rye nucleolar competition (amphiplasty) in triticale by silver-staining procedure. Theor. Appl. Genet., 67, 207-213.

LACADENA, J. R., CERMEÑo, M. C., OREllaNA, J. AND SANTOS, J. L. 1984b. Analysis of nucleolar activity in Agropyron elongatum, its amphiploid with Triticum aestivum and the chromosome addition lines. Theor. Appl. Genet., 68, 75-80.

MARTINI, G., O'DELL, M. AND FLAVELL, R. B. 1982. Partial inactivation of wheat nucleolus organisers by the nucleolus organiser chromosomes from Aegilops umbellulata. Chromosoma, 88, 149-155.

MEDINA, F. J., RISUEÑO, M. C., SANCHEZ-PINA, M. A. AND FERNANDEZ-GOMEZ, M. E. 1983. A study of nucleolar silver staining in plant cells. The role of argyrophilic proteins in nucleolar physiology. Chromosoma, 88, 149-155.

MILlER, D. A., DEV, V. G., TANTRAVAHI, R. AND MILlER, O. J. 1976a. Suppression of human nucleolus organizer activity in mouse-human somatic hybrid cells. Exp. Cell Res., 101, 235-243.

MILlER, O. J., MILLER, D. A., DEV, V. G., TANTRAVAHI, R. AND CROCE, C. M. 1976b. Expression of human and suppression of mouse nucleolar organizer activity in mouse-human somatic cell hybrids. Proc. Nat. Acad. Sci., 73, 4531-4535. 
Navashin, M. S. 1928. Amphiplastie- eine neue karyologische Erscheinung. Proc. Int. Conf. Genet., 5, 1148-1152.

NAVASHIN, M. S. 1934. Chromosome alterations caused by hybridization and their bearing upon certain general genetic problems. Cytologia, 5, 169-203.

ORELLANA, J., SANTOS, J. L., LACADENA, J. R. AND CERMEÑO, M. C. 1984. Nucleolar competition analysis in Aegilops ventricosa and its amphiploids with tetraploid wheats and diploid rye by silver-staining procedure. Can. J. Genet. Cytol., 26, 34-39.

RIEGER, R., MICHAELIS, A. AND GREEN, M. 1976. Glossary of Genetics and Cytology. Classical and molecular. Springer, Berlin, Heidelberg, New York, 647 pp.

SANTOS, J. L., LACADENA, J. R., CERMENO, M. C. AND ORELLANA, J. 1984. Nucleolar organiser activity in wheat-barley chromosome addition lines. Heredity, 52, 425-429.

SATO, S., HIZUME, M. AND KAWAMURA, S. 1980. Relationship between secondary constrictions and nucleolus organizer regions in Allium sativum chromosomes. Protoplasma, 105, 77-85.

TEOH, S. B. AND HUTCHINSON, J. 1983. Interspecific variation in $C$-banded chromosomes of diploid Aegilops species. Theor. Appl. Genet., 65, 31-40.

TEOH, S. B., HUTCHINSON, J. AND MILLER, T. E. 1983a. A comparison of the chromosomal distribution of clones repetitive DNA sequences in different Aegilops species. Heredity, $51,635-641$.

TEOH, S. B., MILLER, T. E. AND READER, S. M. $1983 \mathrm{~b}$. Interspecific variation in $C$-banded chromosomes of Aegilops comosa and Ae, speltoides. Theor. Appl. Genet., 65, 343-348.

WARBURTON, D. AND HENDERSON, A: S. 1979. Sequential silver staining and hybridization in situ on nucleolus organizer regions in human cells. Cytogenet. Cell Genet., 24, 168-175.

ZOHARY, D. AND FELDMAN, M. 1962. Hybridization between amphidiploids and the evolution of polyploids in the wheat (Aegilops-Triticum) group. Evolution, 16, 44-61. 